\title{
Maternal Aromatase Inhibition Effects on RFamide- Related Peptide-3 and Gonadotropin Releasing Hormone in Adult Murine Offspring With Polycystic Ovary Syndrome
}

\section{Zahra Shaaban ( $\nabla$ z.shaban91@yahoo.com )}

Shiraz University School of Agriculture https://orcid.org/0000-0002-2724-1010

\section{Amin Tamadon}

The Persian Gulf Marine Biotechnology Research Center, The Persian Gulf Biomedical Sciences

Research Institute

Mohammad Reza Jafarzadeh Shirazi

Department of Animal Science, College of Agriculture

Mohammad Javad Zamiri

Department of Animal Science, College of Agriculture

Amin Derakhshanfar

Diagnostic Laboratory Sciences and Technology Research Center, School of Paramedical Sciences

\section{Research}

Keywords: Gonadotropin releasing hormone, Hypothalamus, Letrozole, PCOS, Rat, Prenatal, RFamiderelated peptide-3

Posted Date: November 13th, 2020

DOl: https://doi.org/10.21203/rs.3.rs-104558/v1

License: (c) (1) This work is licensed under a Creative Commons Attribution 4.0 International License. Read Full License 


\section{Abstract}

Background: Despite the prevalence of polycystic ovary syndrome (PCOS) among childbearing women and the development of many animal models for this syndrome, information on its etiology is still scarce. Intrauterine hyperandrogenic environment may underlie changes at the levels of hypothalamus, pituitary and ovary organization in female offspring, and PCOS later in life. Letrozole, has been shown to mimic reproductive and metabolic characteristics of PCOS in adult rodent models. Therefore, the aim of this research was to assess the condition in a prenatal letrozole-treated rat model.

Methods: Twenty-eight female rats from dams receiving letrozole at certain doses during late pregnancy were used in the trial. Pregnant Sprague-Dawley rats $(n=21)$ received letrozole treatment on days 16-18 gestation at doses $1.25,1.0,0.75,0.5$, and $0.25 \mathrm{mg} / \mathrm{kg}$ body weight (BW).

Results: Prenatal letrozole-treatment delayed parturition time and reduced the litter size in pregnant dams $(P<0.0001)$. Late puberty onset, irregular ovarian cyclicity, increased anogenital distance (AGD), body weight gain, and serum testosterone concentration and reduced estradiol levels $(P<0.0001)$ were observed in the female offspring of dams receiving 1.25 and $1 \mathrm{mg} / \mathrm{kg}$ BW letrozole. Furthermore, Letrozole at 1.25 and $1 \mathrm{mg} / \mathrm{kg}$ BW showed increased Rfrp and decreased Gnrh mRNA expression $(P<0.0001)$.

Conclusions: Letrozole treatment at doses $1 \mathrm{mg} / \mathrm{kg} \mathrm{BW}$ and lower was not feto-toxic. It was concluded that $1 \mathrm{mg} / \mathrm{kg}$ BW letrozole may be suggested for prenatal PCOS induction.

\section{Background}

Polycystic ovary syndrome (PCOS) is a gynecological disorder along with clinical or biochemical manifestation of hyperandrogenism and menstrual problems (1). Despite abundant information, there is a lack of a precise definition of its pathogenic mechanisms and animal models that accurately reflect the features of human PCOS. The underscored endocrine features of PCOS are hyperandrogenism and LH hypersecretion (2). According to the $\mathrm{NIH}$, Rotterdam, and AE-PCOS conferences, hyperandrogenism is the most important diagnostic criteria of PCOS (3). Among androgenic animal models of PCOS, prenatal androgenized PCOS models displayed a set of reproductive and metabolic features of human PCOS (4). Androgen exposure during intrauterine life created a phenocopy of reproductive and metabolic features of PCOS in adult female rats (5). In pregnant women with PCOS, higher circulating levels of testosterone than in normal pregnant women were reported (6). Notwithstanding the fact that differentiation of hypothalamic centers regulating reproductive and ovarian activity (folliculogenesis and ovulation) occurs during the fetal life (7), hormonal abnormalities during pregnancy can influence reproductive regulating centers in the hypothalamus.

To create a hyperandrogenic environment during pregnancy, we used letrozole because it has the ability to mimic reproductive and metabolic characteristics as observed in PCOS, and also induces ovulation in PCOS women as therapeutic drug. In addition, letrozole can affect the neuronal pathways in the brain 
that control gonadotropin secretion by disrupting the mechanism through which testosterone is converted to estrogen, and these effects can be transmitted epigenetically to the female fetus. Therefore, the use of these drugs in pregnant PCOS women may have adverse effects on their offspring at adulthood. Letrozole, a non-steroidal aromatase inhibitor, created hyperandrogenism and polycystic ovarian morphology in rats (8), and has been introduced as the second drug line for PCOS. Letrozole lacks peripheral anti-estrogenic effects and has a higher pregnancy rate than clomiphene citrate. Furthermore, letrozole is less costly than other ovulation- stimulating preparations, with a therapeutic efficacy similar to gonadotropin agonists (9). In a retrospective cohort study, the offspring of mothers treated with letrozole and clomiphene citrate had 2.5 and $3.9 \%$ chromosomal abnormalities, respectively (9). Accordingly, we aimed to determine the optimal dose of letrozole for prenatal PCOS induction in female rats by assessing the reproductive, endocrine PCOS phenotypes and the hypothalamus-pituitary-gonad (HPG) axis alterations via evaluation of the mRNA expression of Gnrh and Rfrp genes.

Up to now, a number of studies have highlighted that prenatal testosterone exposure disrupted HPG axis differentiation (10-12). Recent evidence suggested that prenatal exposure with androgens led to insensitivity of $\mathrm{GnRH}$ neurons to the negative feedback of steroids resulting in elevated LH levels in rodents $(10)$, Rhesus monkeys $(10,11)$, guinea pig $(10,11)$ and non-human primates $(10)$. In addition, fetal androgen excess in rats affects the hypothalamic-pituitary axis and LH secretion (12). But there has been no model to induce PCOS using letrozole in the prenatal period so far. It is plausible that increased levels of maternal androgens by the mechanism of action of letrozole could cause changes in HPG axis differentiation including GnRH and RFRP-3 neuropeptides. Our previous study showed that by inducing PCOS in adult rats using 90-day constant light, along with crating a typical PCOS model, decreased RFRP3 gene expression in the dorsomedial nucleus (DMN) (13). Based on this previous finding, the question arose as to whether letrozole was able to produce a typical prenatal PCOS model. Secondly, whether it would lead to changes in the hypothalamic level and major reproductive neuropeptides. Therefore, the present study was designed to determine the optimal dose of letrozole for prenatal PCOS induction in a rat model, and to evaluate a number of endocrine, neuroendocrine and reproductive features.

\section{Materials And Methods}

\section{Ethics}

All procedures were approved by the Ethics and Research Committee of Shiraz University (Approval ID: IR.SUMS.REC.1397.434; Approval date: 2018-08-01), and carried out in accordance to the health instructions for the care and use of animals.

\section{Animals}

Adult (8-week-old) female Sprague-Dawley rats $(\mathrm{n}=30)$ weighing between 130 to $180 \mathrm{~g}$ were obtained from the Center of Comparative and Experimental Medicine, Shiraz University of Medical Sciences. The animals were kept in normal experimental condition at $12-12 \mathrm{~h}$ light-dark period, $23 \pm 3^{\circ} \mathrm{C}$, and $25 \pm 5 \%$ humidity, having free access to the pelleted rat food and water. 
After adaptation, vaginal smears were obtained from the rats by vaginal douching and the stages of the estrous cycle were determined based on the appearance of nucleated epithelial cells and cornified cells. The rats in proestrous or estrous phases $(n=21)$ were joined with sexually experienced adult male rats (375 g mean weighing) at 2:1 female/male ratio overnight. The next morning, the rats were examined for the presence of the vaginal plug which was recorded as the sign of mating and the first day of pregnancy (gestation day: GD1).

\section{Prenatal letrozole induction of PCOS}

Pregnant rats were randomly divided into letrozole-treated, control and sham group. The optimal dose of letrozole was in a pilot trial designed to determine the safe doses of letrozole that showed no feto-toxic effects but could induce PCOS in the adult female offspring. Letrozole doses over $1.25 \mathrm{mg} / \mathrm{kg}$ resulted in parturition delay, fetal absorption, uterine infection, and pup mortality.

Due to the fact that, our main goal was to induce changes in ovarian, endocrine, and neuroendocrine levels in female offspring to develop PCOS phenotypes, safe and non-lethal doses were selected. Twentyone pregnant rats ( $\mathrm{n}=3$ for each group) were orally administrated with letrozole (L6545, Sigma-Aldrich, St. Louis, USA) dissolved in $1 \%$ carboxymethylcellolose (CMC, C5013, Sigma-Aldrich, St. Louis, USA) at concentrations of $0.25,0.5,0.75,1.0$, and $1.25 \mathrm{mg} / \mathrm{kg} \mathrm{BW}$ during GDs 16,17 and 18 . In other words, letrozole doses were chosen to increase blood androgen levels higher than physiological levels that lead to PCOS development. Furthermore, GDs 16, 17 and 18 was chosen for letrozole administration owing to the brain differentiation for inactivation of the LH surge center occurs in the late pregnancy of rat (14), and is practically an aromatase peak occurs late in gestation and neonatal life (15). The sham group received vehicle only; $1 \% \mathrm{CMC}$ dissolved in distilled water, and the control rats were untreated. Upon parturition, data including the parturition date, litter size, pup gender, and pup birth weight were recorded. The pups were kept with their mothers until weaning.

At weaning on postnatal day (PND) 21, the pups were sexed and weighed again. The anogenital distance (AGD) was measured using a caliper. The AGD index (AGDI) was calculated in order to normalize the AGD for body weight at weaning. The AGDI was calculated as AGD/BW $\times 100$ (16). After weaning, female offspring were separated in each group $(n=4)$. The female pups $(n=4$ per group from more than one dam), maintained under standard conditions, were weighed every two days from weaning until the end of the study. After one-week post weaning (on PND 28), the female offspring were checked for vaginal opening as the sign of puberty. Vaginal smears were evaluated from 28 PND for 4 weeks to determine the phases of the estrous cycle (17).

\section{Tissue and blood sampling}

Four weeks after estrous cycle observation, due to the unavailability of other anesthetics, chloroform (Merck, KGaA, index No, 602-006-00-4) was used for momentary anesthesia. The rats in each group were euthanized temporary with a few drops of chloroform distributed on cotton in the desiccator. After that, blood was collected by cardiac puncture in tubes without anticoagulant, blood serum was prepared by 
centrifugation at $3000 \mathrm{rpm}$ for $15 \mathrm{~min}$. Blood serum was stored at $-20^{\circ} \mathrm{C}$ until evaluation of testosterone, estradiol, progesterone, follicle stimulating hormone (FSH) and luteinizing hormone (LH).

Immediately after blood sampling and then cervical dislocation, the brain was removed from the skull, and was sampled for real-time PCR analyses of GnRH and RFRP-3 relative gene expression. The mammillary bodies were separated from the inferior and then optic chiasm from the posterior parts of the brain. Finally, with third coronal cut, the diencephalon was removed and the pre-optic area (POA) and dorsomedial nucleus (DMN) was dissected in a piece of aluminum foil and immediately transferred into liquid nitrogen. Following decapitation, the ovaries were fixed in $10 \%$ buffer formalin. The blood and tissue sampling were performed regardless of the stage of the estrous cycle.

\section{Hormone analysis}

Serum concentration of testosterone, estradiol and progesterone were measured by a competitive chemiluminescent enzyme immunoassay (IMMULITE 2000 System Analyzer, Cat. No. L2KTW2, L2KE22 and L2KPW2, respectively), and FSH and LH levels were determined by Rat FSH ELISA Kit and Rat LH ELISA Kit via radioimmunoassay technique (Rainbow Biotechnologies Co., Cat. No. E0179Ra and E0182Ra, respectively).

\section{Histological evaluation}

The fixed ovaries were washed in phosphate-buffered saline (PBS), dehydrated in ascending concentrations of alcohol and embedded in paraffin. Every ten serial sections $(5 \mu \mathrm{m})$ were deparaffinized at $60^{\circ} \mathrm{C}$, transferred into ascending concentrations of ethanol, and then xylene, and stained with hematoxylin and eosin (H\&E). The number of total follicles including: primary, secondary, tertiary or antral follicles and also atretic and cystic follicles, and corpora lutea were counted using a light microscope (CX21, Olympus, Japan) by one person blinded to the origin of the sections. For qualitative observations, three sections per animal from the beginning, middle and end of the ovarian tissue were evaluated using a digital camera (Nikon, NI_U 2013, Japan).

\section{Expression levels of hypothalamic RFRP-3 and GnRH mRNA}

Total RNA was extracted according to the manufacturer's extraction kit (Parstous RNA Isolation Kit, Parstous, Mashhad, Iran), and the pure extracted RNA was kept at $-80^{\circ} \mathrm{C}$. The total purified RNA was measured by ultraviolet spectrophotometry (Nano-Drop, ND1000, USA). Removal of contamination was performed using the DNase I, RNase-free kit (Fermentas EN0521 DNasel (RNase free)).

Based on the cDNA synthesis kit instructions (Smobio, Taiwan), the primers and dNTPs as well as first strand cDNA buffer were mixed in a final volume $20 \mu \mathrm{L}$, then incubated in $37^{\circ} \mathrm{C}$ for 50 min and $85^{\circ} \mathrm{C}$ for 5 min. Finally, for RNA removal, $1 \mu \mathrm{L}$ RNase-H was added to each reaction medium and then incubated at $37^{\circ} \mathrm{C}$ for $20 \mathrm{~min}$. Prepared cDNA was preserved at $-20^{\circ} \mathrm{C}$. To setup the annealing temperature, $\mathrm{cDNA}$ specimens were amplified by Thermocycler (StepOne ${ }^{\text {TM }}$ Real-Time PCR, System Applied Biosystems, Carlsbad, CA). 
The primers for target genes RFRP-3 and GnRH and the reference gene, $\beta$-actin, were designed by Primer3 Software (Table 1). For each reaction of real-time PCR, a mixture of $10 \mu \mathrm{L}$ SYBR Green (TaKaRa, Dalian, China), $7 \mu \mathrm{L}$ distilled water, $1 \mu \mathrm{L}$ forward primer, $1 \mu \mathrm{L}$ reverse primer and $1 \mu \mathrm{L}$ cDNA was prepared in a final volume of $20 \mu \mathrm{L}$. Eventually, the amplification process was carried out by StepOnePlus Real-Time PCR Systems (Bioneer, South Korea) and the CT values were recorded by real-time PCR software. For evaluation of relative mRNA expression of RFRP-3 and $G n R H$, the quantitative examination of CT values was carried out using the $2^{-\Delta \Delta C T}$ formula.

\section{Statistical analysis}

Evaluation of data normality was conducted by the Kolmogorov-Smirnov test. For multiple comparisons among groups one-way ANOVA and post-hoc Tukey was used. Binomial data were analyzed by the Chisquared test. Multiple comparisons were carried out by Kruskal-Wallis-H test for the data that were not normal. For weight gain values from letrozole-treated, control and sham groups were compared using repeated measure ANOVA. The differences among groups were considered statistically significant when $P \otimes 0.05$. For data analysis, the SPSS 22 for windows (IBM SPSS Statistics for Windows, version 22, IBM Inc., Chicago, Illinois) was used. The data are reported as mean \pm standard error of the mean (SEM). Charts were created by GraphPad Prism version 5.01 for Windows (GraphPad Inc. Inc., San Diego, CA, USA).

\section{Results}

Oral administration of letrozole to rats on days 16,17 and 18 of pregnancy impacted on the gestation length $(P<0.0001)$, number of neonates born (litter size) $(P<0.0001)$, and male/female ratio $(P=0.0369)$ (Figure 1-A, B, C). Longer gestation length was observed in the $1.25 \mathrm{mg} / \mathrm{kg} \mathrm{BW}$ group compared to control and sham groups. Furthermore, in the $1 \mathrm{mg} / \mathrm{kg} B W$ group, an increase in gestation length was observed compared to the $0.5,0.25 \mathrm{mg} / \mathrm{kg} B W$ and sham groups $(P=0.0093)$. In the pilot experiment evaluating the safe doses of letrozole in pregnant rats, doses higher than $1 \mathrm{mg} / \mathrm{kg} \mathrm{BW}(1.5$ to $3 \mathrm{mg} / \mathrm{kg})$ on 16, 17 and 18 GDs delayed delivery, and needed cesarean section (data not shown).

A significant decrease in litter size was observed at $1.25 \mathrm{mg} / \mathrm{kg} \mathrm{BW}(P<0.0001)$. The pilot experiment also revealed that higher doses also reduced the litter size, and increased neonatal mortality and fetal absorption (data not shown).

The offspring male/female ratio in the $1 \mathrm{mg} / \mathrm{kg}$ BW group was lower than the sham and $0.75 \mathrm{mg} / \mathrm{kg} \mathrm{BW}$ groups $(P<0.05)$.

\section{AGD and AGDI and puberty onset}

Letrozole treatment increased the anogenital distance (AGD) and AGDI compared to control groups ( $P$ $<0.0001$; Figure 2-A, B), and puberty was delayed (Figure 2-C) at 1.25 and $1 \mathrm{mg} / \mathrm{kg} \mathrm{BW}$ letrozole doses (P $<0.01)$ 


\section{Body weight and ovarian weight}

Letrozole, time and their interaction significantly affected the weight gain in female rats $(P<0.0001)$. Weight gain changes at 6,7 and 8 weeks were higher in letrozole-treated rats than in the control and sham groups $(P<0.01$; Figure 3$)$. There was no effect of letrozole on the ovarian weight $((P=0.14)$.

\section{Estrous cycles}

The pattern of estrous cycles in letrozole-treated groups was different $(P<0.0001$; Figure 4$)$. Absence of cycles and irregular cycles were observed at all doses of letrozole, and the greatest delay in the onset of cycles (first proestrus) after puberty was observed at 1.25 and $1 \mathrm{mg} / \mathrm{kg} \mathrm{BW}$ doses which also recorded a delay in puberty as reported earlier.

The higher percentage of proestrus in the $1 \mathrm{mg} / \mathrm{kg}$ BW group was only significant compared with 0.75 and $1.25 \mathrm{mg}$ doses $(P<0.01)$. The percentage of metestrus at $1 \mathrm{mg}$ dose was lower than at $0.75 \mathrm{mg}$ dose, and the percentage of diestrus at $1.25 \mathrm{mg}$ dose was higher than $1 \mathrm{mg}$ dose $(P<0.01)$. There was no significant difference between the groups in the percentage of estrus $(P=0.37$; Figure $5-A)$ or follicular phase and luteal phases $(P=0.9$; Figure $5-B)$. The number of completed cycles in the control group was higher than other groups $(P<0.05$; Figure $5-C)$.

\section{Ovarian histology}

The total number of primary, secondary, antral and atretic follicles, and the number of corpora lutea in the $0.25 \mathrm{mg} / \mathrm{kg}$ BW group was higher than the other groups $(P<0.0001$; Figure $6-A-B-D)$. However, the number of cystic follicles in 0.25 and $0.75 \mathrm{mg} / \mathrm{kg} B W$ groups was higher than the sham and control rats $(P<0.01$; Figure 6-C).

\section{Serum concentration of steroids and gonadotropins}

Serum testosterone concentration was higher in the $1.25 \mathrm{mg}$ group than the other groups $(P<0.0001)$. Also, in the $1 \mathrm{mg}$ group, testosterone concentration was higher than the other groups except $0.75 \mathrm{mg}$ group ( $P<0.01$; Figure $7-A)$. Serum estradiol levels in $1.25 \mathrm{mg}$ and $1 \mathrm{mg}$ groups was lower than other groups (Figure 7- B). Serum progesterone level was higher in $0.25 \mathrm{mg}$ group than in all groups but not in the 0.5 and sham groups $(P<0.0001$; Figure $7-C)$.

Letrozole treatment of female rats resulted in lower serum concentration of $\mathrm{LH}(\mathrm{P}=0.001$; Figure 7- $D)$ and FSH $(P=0.005$; Figure 7- E). Furthermore, there was no significant difference in LH: FSH ratio, except between 1.25 and $0.5 \mathrm{mg} / \mathrm{kg}$ BW groups $(P=0.014$; Figure $7-F)$.

\section{Gene expression of hypothalamic polypeptides RFRP-3 and GnRH}

The relative expression of RFRP-3 gene increased with increasing dose of letrozole being the highest at $1.25 \mathrm{mg}$ dose; however, $\mathrm{GnRH}$ gene expression decreased due to letrozole treatment $(P<0.0001$; Figure 8$)$. 


\section{Discussion}

The delayed parturition may be due to the reduced level of estrogen induced by letrozole treatment. In fact, high levels of estrogen are necessary for initiation of parturition (18). Letrozole administration at 0.002 or $0.02 \mathrm{mg} / \mathrm{kg}$ BW per day during 15-21 GDs delayed parturition in rat (19). Reduced litter size was observed in $1.25 \mathrm{mg} / \mathrm{kg}$ group, suggesting that letrozole at high doses has severe feto toxic effects. In a study by Zhang et al (20), co-treatment of pregnant rats with DHT $(1.66 \mathrm{mg} / \mathrm{kg} \mathrm{BW}$ per day from 7.5-13.5 GDs) and insulin resulted in fetal death and subsequently reduced litter size. Treatment of pregnant rats with $0.02 \mathrm{mg} / \mathrm{kg}$ letrozole at 15-21 GDs caused fetal mortality (19). Letrozole administration during organogenesis (6-16 GDs) in rats at $0.01,0.02$ and $0.04 \mathrm{mg}$ per $\mathrm{kg}$ doses resulted in post implantation loss that included early and late resorption and decreased number of viable fetuses (21). These findings suggested that embryo and feto toxic effects of letrozole depending on the time of administration, were dose-dependent (18). It seems these changes are caused by the letrozole action in reducing estrogen levels because simultaneous estrogen treatment at maximum dose of letrozole $(0.04 \mathrm{mg} / \mathrm{kg} \mathrm{BW})$ restrained the feto toxic effects of letrozole (22). However, increased fetal mortality may be due to the direct effect of the androgen increment as a result of letrozole, as PCOS women have been reported to have higher perinatal fetal mortality rates than women with normal androgen levels (23). The shorter exposure time and higher letrozole dose was the main difference between our study and these studies; so it seems that the disrupting effects of letrozole are related to the specific (organogenesis or fetal stage) time during pregnancy (18). and the administrated dose. In our study, the moderate effect of higher letrozole dose on fetal mortality could be due to administration at the late pregnancy, that is, letrozole had the greatest effect on fetal viability. Generally, the letrozole mediated embryo or feto toxic effects were dose dependent and the administered dose in pregnant rats in at least $1 \%$ of the maximum dose prescribed to humans on a daily basis resulted in fetal or embryonic death (24). Due to the fact that estrogen is greatly increased in the last third of rat pregnancy (24) and rodent ovaries are the prominent site of estrogen biosynthesis throughout pregnancy (18), inhibition of estrogen synthesis in the ovary in late pregnancy causes adverse effects on maternal and fetal aspects of pregnancy in rats as observed in our study with increasing dose.

This work highlighted delayed puberty as a result of 1.25 and $1 \mathrm{mg} / \mathrm{kg} \mathrm{BW}$ prenatal letrozole treatment. Commonly, vaginal opening in rats occurs at 28-49 postnatal days (PNDs), but the age of puberty onset and beginning of sexual maturation is different according to the species and growth rate (25). Delayed puberty in our study, may be due to increased Rfrp expression. Similarly, in a study by Han et al (26) it was shown that intracerebroventricular injection of RFRP-3 between days 28 and 36 , at the time of puberty onset, delayed vaginal opening in rats. Furthermore, Rfrp expression in DMN decreased during early pre-pubertal stages in the mouse. This reduces its inhibitory effect on $\mathrm{GnRH}$ neurons (27). Similarly, GPR147 (the RFRP-3 receptor) knockout on GnRH neurons caused delayed puberty in mice (27). The increased expression of $R f r p$ may be due to elevated androgen levels during the intrauterine life but this hypothesis should be investigated further by evaluating the AR on RFRP-3 neurons or by blocking the direct effects of androgen by flutamide. 
The letrozole androgenized female rats showed longer anogenital distance (AGD) at puberty than untreated groups. Furthermore, we observed increased AGD in all treated groups. The anogenital distance (AGD) and anogenital distance index (AGDI) are both main indicators of maternal hyperandrogenism (28). In general, AGD is longer in the male rats than in the female ones, so ADG in female reflects the degree of uterine hyperandrogenism that she experienced during the intrauterine life and the higher doses of androgen exposure during fetal life led to the longer AGD in female offspring. Consistent with our data, longer AGD caused by prenatal testosterone administration on 20 GD was reported (29). In addition, the long AGD in prenatal T and DHT (on 16-19 GDs) female rats was shown (30). Increased AGD reflects the androgenic effect of letrozole during the time of external genitalia differentiation. External genitalia differentiation in female rat occurs during late pregnancy (19-20 GDs), underlying the direct effect of dihydrotestosterone (31). DHT is a non-aromatizable androgen and acts like an aromatase inhibitor, therefore, letrozole and DHT have the same effect on AGD changes mediated by androgen increments. These findings suggest that androgen action during embryonic life, especially at the time of external genitalia differentiation, affects AGD, which is a good indicator of direct effect of androgens.

Prenatal letrozole administration at $1.25,1.0$ and $0.75 \mathrm{mg} / \mathrm{kg} \mathrm{BW}$ significantly increased the body weight gain compared with other groups. These body weight gain increments were greater than control groups at 6 to 8 postnatal weeks, suggesting the metabolic effects of prenatal letrozole appeared at adulthood. Increased body weight gain as a metabolic feature of PCOS has been confirmed in various adult letrozole induced PCOS models in the rat $(8,32-34)$. and also in DHT PCOS induction model in mice (35). Arroyo et al. (36) reported that prepubertal letrozole model caused increased body weight gain in mice which did not improve with letrozole removal, contrary to the reproductive traits induced in this model that were completely recovered. However, in another study, weight gain caused by adult letrozole PCOS model was reversible by flutamide in mice (37). These findings suggested that metabolic alterations such as body weight gain by prenatal or prepubertal origins were more permanent.

In the current study, all letrozole treated groups exhibited acyclicity. Moreover, the delay in initiation of cycles (first proestrus) and reduced number of females that were able to complete one or more cycles were observed in all treated groups. In our study, the total number of growing follicles, atretic follicles, cystic follicles and corpora lutea was higher at $0.25 \mathrm{mg} / \mathrm{kg} \mathrm{BW}$ letrozole. Irregular cycles and ovulation dysfunction are the usual effect of exposure to androgen excess during intrauterine life $(38,39)$. It seems that anovulatory cycles arise from androgen mediated functions, because flutamide as an androgen receptor antagonist could recover ovulatory cycles in prenatal androgenized female mice (40). Irregular cycles, fewer corpora lutea and ovarian cysts formation were shown as a result of prenatal DHT treatment in wild-type mice, but these effects were not observed in $A R$ knockout mice indicating the key role of androgen signaling in creating PCOS-like features (41). Increased number of antral and preantral follicles was observed in prenatal rats exposed to androgen on 16-19 GDs but not on 20 GD (29), indicating that the timing of androgen administration is important. Induction of testosterone and dihydrotestosterone at the end of gestation had no effect on polycystic ovarian development, although it induced irregular and anovulatory cycles $(7,30)$. 
In PCOS women, the high number of preantral and antral follicles results in antral cavity expansion, cyst formation, thin granulosa layers and thick theca layers (42). Similar to our results, fetal and postnatal treatment of testosterone in rat led to arrested follicular development in the small antral (preantral) follicle (43). In our prenatal letrozole model, the number of antral (small antral) follicles was higher. Androgens stimulate the growth of small antral follicles (44), but at the advanced stages of follicular development they suppress the growth of follicles by granulosa apoptosis in the preovulatory follicles (45). Therefore, hyperandrogenism induced by letrozole severely impairs normal follicular development (46). Taken together, letrozole administration via increasing the levels of testosterone may influence ovarian follicular development and finally disrupt ovarian cycles showing the direct effect of androgen action on the ovary. However, this effect of letrozole should be investigated using in vitro studies in which the ovaries of female fetuses are exposed to androgen excess by letrozole. It is also interesting to evaluate the recovery effect of flutamide in prenatal letrozole models of PCOS to determine the definitive effect of androgens.

The findings of our research showed markedly elevated testosterone levels and reduced estradiol levels in 1.25 and $1 \mathrm{mg} / \mathrm{kg}$ BW groups. Serum FSH and LH levels were also higher in control groups showing that gonadotropins levels were not affected by prenatal androgenization via letrozole. However, progesterone concentration, in proportion to the higher number of corpora luteua in the $0.25 \mathrm{mg} / \mathrm{kg} \mathrm{BW}$ group, was the highest in this group. Letrozole treatment in adult female rats for 14 days resulted in reduced estradiol levels (18). Increased LH levels, as a main feature of PCOS women, has also been observed in adult rodent letrozole models (47-49). In the present study, serum LH levels at $1.25 \mathrm{mg} / \mathrm{kg}$ BW were increased compared with other groups. In prenatal androgenized female rats, FSH levels were not affected by androgen action $(29,30)$. In our study, Serum FSH concentration decreased in letrozole treated groups vs control groups. There have been inconsistencies in the baseline and pulse concentration of LH and FSH in various PCOS prenatal and clinical studies of PCOS women $(7,40,50)$. These inconsistencies may be due to the different estrous phases of female rats during sampling, animal models and species, time of induction and other experimental conditions. In letrozole treated animals, increased endogenous androgen production by inhibiting aromatase function is unavoidable, and has been reported in different models of PCOS induction with letrozole (51-53). In our study, consistent with previous findings, considerable increase in testosterone at 1.25 and $1 \mathrm{mg} / \mathrm{kg}$ BW was recorded, as well as decreases in estradiol levels. In daughters of women with PCOS, increased testosterone levels were reported during puberty but in general there is little information available (54). Serum estradiol levels did not change in PCOS induced by prenatal testosterone administration (29) and also adult letrozole model $(33,48,53)$. But in another studies, reduced estradiol levels were reported in letrozole treated PCOS adult rat model $(32,52)$. Given that estradiol levels vary during the estrous cycle, and estradiol is at the lowest level in estrous phase, these differences are probably due to measurements taken at different times during the estrous cycle. On the other hand, variations in estradiol levels are the direct effects of letrozole due to reducing the conversion testosterone to estradiol.

In addition, decreased Gnrh gene expression as a result of prenatal letrozole treatment in female rats was proved. Letrozole induced mouse model of PCOS showed increased expression of gonadotropin releasing 
hormone receptor (Gnrhr) in the pituitary, that was not reversible by flutamide treatment (37). Moreover, increased hypothalamic Gnrh and pituitary Gnrhrtranscripts were observed in an adult rat model induced by 21 days 0.5 mg letrozole administration (53). In another adult letrozole PCOS model, no changes in Gnrh mRNA expression, but increased pituitary GnrhrmRNA expression was observed (47). Moreover, an elevated number of $\mathrm{AR}$ and $\mathrm{GnRH}$ immunoreactive cells and $A R \mathrm{mRNA}$ expression were shown due to DHT induced PCOS in adult rats (55). The lack of prenatal androgenization PCOS studies evaluating Gnrh expression, and inconsistencies in studies of PCOS induction with letrozole in adulthood complicate the interpretation of results. However, the mechanism that indicates an increase in Gnrhr expression appears to be more influential in the etiology of PCOS (47). On the other hand, puberty onset is controlled by high frequency $\mathrm{GnRH}$ neurons that affect FSH and LH release to trigger gonads for puberty initiation (26); therefore, the elevated Gnrh expression in our study in untreated group may be due to the normal neuroendocrine changes at puberty onset. At the same time, decreased Gnrh expression in letrozole treated groups led to late puberty. However, it would be better to investigate the direct effect of androgens using flutamide during pregnancy on these neuroendocrine changes, which was not performed in our study due to budget constraints.

In addition, the impact of upstream mechanisms on $\mathrm{GnRH}$ control should not be overlooked. In prenatal androgenization mice models, the putative $\gamma$-aminobutyric acid GABAergic synaptic connections to $\mathrm{GnRH}$ neurons was elevated at adulthood; suggesting an increase in $\mathrm{GnRH}$ neurons pulse and frequency due to the effect of GABAergic neurons via mediating the negative feedback of steroids (40,56-58). In addition, prenatal androgenized female rats by testosterone displayed decreased progesterone receptor $(P g r)$ mRNA expression in the hypothalamic POA indicating the capability of prenatal androgen in creating alteration in the $\mathrm{GnRH}$ neurosecretory system and neuroendocrine dysfunctions at adulthood such as infertility related to PCOS (39). Moreover, some abnormalities in KNDy neuropeptides secretion were shown in various animal models of PCOS; for instance, prenatal testosterone treated ewes showed KNDy expression abnormalities (59). In a study by Caldwell et al. (41), prenatal administration of DHT did not alter the KNDy neuropeptides. Furthermore, adult PCOS models are noteworthy in this field. Letrozole treated adult female mice revealed an increased neuronal activation of Kiss1 (60). A DHT induced PCOS rat model resulted in decreased kiss 1 gene expression, but the serum levels of testosterone, estradiol, $\mathrm{LH}$, FSH were unaltered (61). Interestingly, in a letrozole induced PCOS model in adult rats, increased positivecell number of kisspeptin in the arcuate and decreased number of positive kisspeptin in anteroventral periventricular (AVPV) nucleus were reported (62). Kisspeptin neurons in the arcuate nucleus are involved in the negative feedback of estradiol on the $\mathrm{GnRH} / \mathrm{LH}$ system. On the other hand, kisspeptin neuropeptides of the AVPV mediate preovulatory LH surge (63). Therefore, increased kiss 1 gene expression in the arcuate nucleus can interfere with the PCOS pathology (62). In general, the effect of prenatal and adult administration of androgens on inhibitory and excitatory regulators of GnRH neurons is likely more important than the direct impact of androgens on these neurons.

Compared with other groups, increased expression of Rfrp gene in the hypothalamic DMN was observed at 1.25 and $1 \mathrm{mg} / \mathrm{kg}$ BW letrozole treatment. Prepubertal letrozole implants releasing $50 \mu \mathrm{g} / \mathrm{day}$ for 16 days before puberty did not impact on Rfrp expression in DMN; however, increased LH levels were found 
in adult female rats suggesting the role of other endogenous regulators of GnRH such as KNDy neuropeptides or GABAergic inputs rather than RFRP-3 neurons (60). Moreover, in our previous study, constant light induced PCOS rat model decreased Rfrp expression, along with unaltered FSH and LH serum levels in adult female rats (13). Furthermore, in neonatal testosterone treated female rats, decreased Rfrp mRNA expression was reported, without any effect on LH serum level (64). These studies revealed that serum LH concentration did not reflect the effect of Gnrh and Rfrp expression changes directly. In other words, the changes in the expression of these neuropeptides are probably not the main neuroendocrine mechanism for LH increase in PCOS women. On the other hand, it was shown that the intracerebroventricular injection of RFRP-3 decreased Gnrh mRNA expression in female rats (26), demonstrating the inhibitory effect of RFRP-3 on GnRH neurons. These results are consistent with our study. It has also been shown that the number of Rfrp expressing neurons in adulthood is lower than at birth in both sexes of mice (65). Therefore, alteration in Rfrp expression in control groups is normal for the ages after puberty onset, but in treated group, especially at 1.25 and $1 \mathrm{mg} / \mathrm{kg} \mathrm{BW}$, enhanced $R f r p$ expression may be as a result of excessive androgen production during intrauterine life.

In various models, alterations in Gnrh expression or basal or pulsatile levels of GnRH neuropeptide are different. This might be due to the fact that different neural pathways influence the GnRH neurons (60). In spite of the fact that, there are limitations due to the lack of information on $\mathrm{GnRH}$ pulse frequency and amplitude, so the baseline value of serum LH levels cannot be attributed to the pulsatile GnRH secretion and also Gnrh gene expression. Given the fact $\mathrm{GnRH}$ secretion is affected by a set of stimulatory and inhibitory factors, including KNDy neuropeptides and gamma-aminobutyric acid (GABA)ergic neurons, further studies are needed to evaluate the changes in upstream $\mathrm{GnRH}$ regulators, especially in prenatal PCOS models.

\section{Conclusion}

In summary, the results of our study suggested that prenatal letrozole treatment at doses lower than 1 $\mathrm{mg} / \mathrm{kg} \mathrm{BW}$ is safe and has no detrimental embryotoxic and lethal effects on fetuses and mothers in Sprague-Dawley rats. A comprehensive dose response study was carried out to evaluate the alterations of major genes controlling reproductive phenomena, Gnrh and Rfrp, steroid hormones and gonadotropins and ovarian function in response to prenatal letrozole administration. We recorded irregularities in estrous cycles, follicular development changes, increased testosterone levels, decreased estradiol levels, decreased Gnrh, increased Rfrp expression at 1.25 and $1 \mathrm{mg} / \mathrm{kg}$ BW letrozole. Due to the greater effect of $1.25 \mathrm{mg} / \mathrm{kg}$ BW treatment on fetal mortality, we finally concluded that prenatal letrozole treatment at 1 $\mathrm{mg} / \mathrm{kg}$ BW on 16-18 GDs in the rat, is probably optimal for PCOS induction by inhibiting aromatase and indirectly increasing endogenous androgen levels. In terms of future work, it would be interesting to examine the upstream and downstream pathways that control the GnRH and RFRP-3 neurons. Another possible area of future research would be to investigate whether there is a relationship between these neuroendocrine pathways and changes in androgen levels. 


\section{Abbreviations}

AE-PCOS: Androgen Excess and PCOS Society

AGD: Anogenital distance

AGDI: Anogenital distance index

AVPV: Anteroventral periventricular

BW: Body weight

CMC: Carboxymethylcellolose

DHT: Dihydrotestosterone

DMN: Dorsomedial nucleus

FSH: Follicle stimulating hormone

GABA: gamma-aminobutyric acid

GD: Gestation day

Gnrh: Gonadotropin releasing hormone

Gnrhr: Gonadotropin releasing hormone receptor

HPG: Hypothalamus-pituitary-gonad axis

KNDy: Kisspeptin/neurokinin B/dynorphin

LH: Luteinizing hormone

NIH: National Institutes of Health Criteria

PBS: phosphate-buffered saline

PCOS: Polycystic ovary syndrome

Pgr: Progesterone receptor

POA: Preoptic area

PND: Postnatal day

Rfrp: RF-amide related peptide 
SEM: Standard error of mean

\section{Declarations}

\section{Ethics approval and consent to participate}

All procedures were approved by the Ethics and Research Committee of Shiraz University (Approval ID: IR.SUMS.REC.1397.434; Approval date: 2018-08-01).

\section{Consent for publication}

Not applicable

\section{Availability of data and materials}

Not applicable

\section{Competing interests}

The authors declare that they have no competing interests.

\section{Funding}

This paper financially was supported by Animal Science Department of Shiraz University through grant Number $97 \mathrm{gcu} 3 \mathrm{~m} 148075$ for PhD students.

\section{Authors' contributions}

Zahra Shaaban conceived of the presented idea and developed, carried out the experimental works, wrote the manuscript, performed the analytical methods, discussed the results and wrote draft of manuscript. Amin Tamadon conceived the original idea, supervised the project, performed the analytical methods, designed the figures and wrote the final version of manuscript.

Mohammad Reza Jafarzadeh Shirazi, provided the grant of project, supervised the project, discussed the results and contributed to the final correction of manuscript.

Mohammad Javad Zamiri, consulted the thesis project. contributed in the final correction of version of manuscript.

Amin Derakhshanfar, discussed the results and contributed to the final correction of manuscript.

All authors read and approved the final manuscript.

\section{Acknowledgements}


The animals were kept and sampled at the Center for Comparative and Experimental Medicine, Shiraz University of Medical Sciences. Other experimental procedures were carried out in the Department of Animal Science, College of Agriculture, Shiraz University, Shiraz, Iran. It is worthwhile to appreciate the esteemed staff of these centers here.

\section{Authors' information}

Zahra Shaaban ${ }^{1 \dagger}$, Amin Tamadon ${ }^{2 \dagger}$, Mohammad Reza Jafarzadeh Shirazi ${ }^{1 *}$, Mohammad Javad Zamiri ${ }^{1}$, Amin Derakhshanfar ${ }^{3,4}$

1. Department of Animal Science, College of Agriculture, Shiraz University, Shiraz, Iran

2. The Persian Gulf Marine Biotechnology Research Center, The Persian Gulf Biomedical Sciences Research Institute, Bushehr University of Medical Sciences, Bushehr, Iran

3. Diagnostic Laboratory Sciences and Technology Research Center, School of Paramedical Sciences, Shiraz University of Medical Sciences, Shiraz, Iran

4. Center of Comparative and Experimental Medicine, Shiraz University of Medical Sciences, Shiraz, Iran

† These authors have same contribution as first authors.

\section{* Corresponding author:}

Mohammad Reza Jafarzadeh Shirazi, PhD; Department of Animal Science, College of Agriculture, Shiraz University, Shiraz, Iran; Tel/fax: +98-71-3228-6073; E-mail: jafarzd@shirazu.ac.ir

\section{Authors' email:}

Zahra Shaaban, z.shaban91@yahoo.com

Amin Tamadon, amintamaddon@yahoo.com

Mohammad Reza Jafarzadeh Shirazi, jafarzd@shirazu.ac.ir

Mohammad Javad Zamiri, mjzamiri@gmail.com

Amin Derakhshanfar, aderakhshanfar@yahoo.com

\section{References}

1. Naeimi SA, Hajimehdipoor H, Saber S. Comparing the Effect of Nigella sativa oil Soft Gel and Placebo on Oligomenorrhea, Amenorrhea and Laboratory Characteristics in Patients with Polycystic Ovarian Syndrome, a Randomized Clinical Trial. Res Rev. J Pharmacogn. 2020;7:49-59.

2. Walters K. Role of androgens in normal and pathological ovarian function. Reproduction. 2015;149:R193-R218. 
3. Lizneva D, Suturina L, Walker W, Brakta S, Gavrilova-Jordan L, Azziz R. Criteria, prevalence, and phenotypes of polycystic ovary syndrome. Fertil Steril. 2016;106:6-15.

4. Tamadon A, Hu W, Cui P, Ma T, Tong X, Zhang F et al. How to choose the suitable animal model of polycystic ovary syndrome? Trad Med Mod Med. 2018;1:95-113.

5. Demissie M, Lazic M, Foecking EM, Aird F, Dunaif A, Levine JE. Transient prenatal androgen exposure produces metabolic syndrome in adult female rats. Am J Physiol Endocrinol Metab. 2008;295:E262E8.

6. Sir-Petermann T, Maliqueo M, Angel B, Lara H, Perez-Bravo F, Recabarren S. Maternal serum androgens in pregnant women with polycystic ovarian syndrome: possible implications in prenatal androgenization. Hum Reprod. 2002;17:2573-9.

7. Caldwell A, Middleton L, Jimenez M, Desai R, McMahon A, Allan C et al. Characterization of reproductive, metabolic, and endocrine features of polycystic ovary syndrome in female hyperandrogenic mouse models. Endocrinology. 2014;155:3146-59.

8. Kafali $\mathrm{H}$, Iriadam M, Ozardalı I, Demir N. Letrozole-induced polycystic ovaries in the rat: a new model for cystic ovarian disease. Med Res Arch. 2004;35:103-8.

9. Sharma S, Ghosh S, Singh S, Chakravarty A, Ganesh A, Rajani S et al. Congenital malformations among babies born following letrozole or clomiphene for infertility treatment. PLoS One. 2014;9.

10. Abbott DH, Dumesic DA, Levine JE, Dunaif A, Padmanabhan V. Animal models and fetal programming of the polycystic ovary syndrome. In: Androgen Excess Disorders in Women: Springer, 2006:259-72.

11. Dumesic DA, Abbott DH, Eisner JR, Goy RW. Prenatal exposure of female rhesus monkeys to testosterone propionate increases serum luteinizing hormone levels in adulthood. Fertil Steril. 1997;67:155-63.

12. Ibáñez L, de Zegher F, Potau N. Anovulation after precocious pubarche: early markers and time course in adolescence. J Clin Endocrinol Metab. 1999;84:2691-5.

13. Shaaban Z, Shirazi MRJ, Nooranizadeh MH, Tamadon A, Rahmanifar F, Ahmadloo S et al. Decreased expression of arginine-phenylalanine-amide-related peptide-3 gene in dorsomedial hypothalamic nucleus of constant light exposure model of polycystic ovarian syndrome. Int J Fertil Steril. 2018;12:43.

14. Bakker J, Baum MJ. Role for estradiol in female-typical brain and behavioral sexual differentiation. Front Neuroendocrinol. 2008;29:1-16.

15. Lephart ED. A review of brain aromatase cytochrome P450. Brain research reviews. 1996;22:1-26.

16. Vandenbergh JG, Huggett CL. The anogenital distance index, a predictor of the intrauterine position effects on reproduction in female house mice. Lab Anim Sci. 1995;45:567-73.

17. Marcondes F, Bianchi F, Tanno A. Determination of the estrous cycle phases of rats: some helpful considerations. Braz J Biol. 2002;62:609-14. 
18. Tiboni GM, Ponzano A. Fetal safety profile of aromatase inhibitors: Animal data. Reprod Toxicol. 2016;66:84-92.

19. Kafali $\mathrm{H}$, Iriadam M. A novel tocolytic agent: Effects of letrozole on gestational length and parturition time. Am J Perinatol. 2007;24:323-6.

20. Zhang Y, Zhao W, Xu H, Hu M, Guo X, Jia W et al. Hyperandrogenism and insulin resistance-induced fetal loss: evidence for placental mitochondrial abnormalities and elevated reactive oxygen species production in pregnant rats that mimic the clinical features of polycystic ovary syndrome. J Physiol. 2019;597:3927-50.

21. Tiboni G, Marotta F, Rossi C, Giampietro F. Effects of the aromatase inhibitor letrozole on in utero development in rats. Hum Reprod. 2008;23:1719-23.

22. Tiboni G, Marotta F, Castigliego A, Rossi C. Impact of estrogen replacement on letrozole-induced embryopathic effects. Hum Reprod. 2009;24:2688-92.

23. Boomsma C, Eijkemans M, Hughes E, Visser G, Fauser B, Macklon N. A meta-analysis of pregnancy outcomes in women with polycystic ovary syndrome. Hum Reprod Update. 2006;12:673-83.

24. Agoreyo F, Okeke O. Quantitative Evaluation of Serum Oestrogen Levels in the Three Trimesters of Pregnancy in Albino Rat. NISEB Journal. 2018;14.

25. Hafez E. Rabbits. Reproduction and breeding techniques for laboratory animals 1970:273-315.

26. Han X, He Y, Zeng G, Wang Y, Sun W, Liu J et al. Intracerebroventricular injection of RFRP-3 delays puberty onset and stimulates growth hormone secretion in female rats. Reprod Biol Endocrinol. 2017;15:1-10.

27. Ancel C, Plate M, Inglis M, Anderson G. SAT-423 The Involvement of GnRH Neurons in Mediating the Effects of RFRP-3 on the Mouse Reproductive Axis. J Endocr Soc. 2019;3:SAT-423.

28. Hurd PL, Bailey AA, Gongal PA, Yan RH, Greer JJ, Pagliardini S. Intrauterine position effects on anogenital distance and digit ratio in male and female mice. Arch Sex Behav. 2008;37:9-18.

29. Tehrani FR, Noroozzadeh M, Zahediasl S, Piryaei A, Hashemi S, Azizi F. The time of prenatal androgen exposure affects development of polycystic ovary syndrome-like phenotype in adulthood in female rats. Int $\mathrm{J}$ Endocrinol Metab. 2014;12.

30. Wu X-Y, Li Z-L, Wu C-Y, LI Y-M, Lin H, Wang S-H et al. Endocrine traits of polycystic ovary syndrome in prenatally androgenized female Sprague-Dawley rats. Endocr J. 2010:1001060376-.

31. Beltrame D, di Salle E, Giavini E, Gunnarsson K, Brughera M. Reproductive toxicity of exemestane, an antitumoral aromatase inactivator, in rats and rabbits. Reprod Toxicol. 2001;15:195-213.

32. Xu G, Zhang A, Liu J, Wang X, Feng J, Chen Y. Effects of Electroacupuncture on Ovarian Expression of the Androgen Receptor and Connexin 43 in Rats with Letrozole-Induced Polycystic Ovaries. J Evid Based Complementary Altern Med. 2020;2020.

33. Manneras L, Cajander S, Holmäng A, Seleskovic Z, Lystig T, Lönn M et al. A new rat model exhibiting both ovarian and metabolic characteristics of polycystic ovary syndrome. Endocrinology. 2007;148:3781-91. 
34. Matsuzaki T, Tungalagsuvd A, Iwasa T, Munkhzaya M, Yanagihara R, Tokui T et al. Kisspeptin mRNA expression is increased in the posterior hypothalamus in the rat model of polycystic ovary syndrome. Endocr J. 2016:EJ16-0282.

35. Nohara K, Laque A, Allard C, Münzberg H, Mauvais-Jarvis F. Central mechanisms of adiposity in adult female mice with androgen excess. Obesity. 2014;22:1477-84.

36. Arroyo P, Ho BS, Sau L, Kelley ST, Thackray VG. Letrozole treatment of pubertal female mice results in activational effects on reproduction, metabolism and the gut microbiome. PLoS One. 2019;14:e0223274.

37. Ryan GE, Malik S, Mellon PL. Antiandrogen treatment ameliorates reproductive and metabolic phenotypes in the letrozole-induced mouse model of PCOS. Endocrinology. 2018;159:1734-47.

38. Birch RA, Padmanabhan V, Foster DL, Unsworth WP, Robinson JE. Prenatal programming of reproductive neuroendocrine function: fetal androgen exposure produces progressive disruption of reproductive cycles in sheep. Endocrinology. 2003;144:1426-34.

39. Foecking EM, Szabo M, Schwartz NB, Levine JE. Neuroendocrine consequences of prenatal androgen exposure in the female rat: absence of luteinizing hormone surges, suppression of progesterone receptor gene expression, and acceleration of the gonadotropin-releasing hormone pulse generator. Biol Reprod. 2005;72:1475-83.

40. Sullivan SD, Moenter SM. Prenatal androgens alter GABAergic drive to gonadotropin-releasing hormone neurons: implications for a common fertility disorder. Proc Natl Acad Sci. 2004;101:712934.

41. Caldwell A, Eid S, Kay C, Jimenez M, McMahon A, Desai R et al. Haplosufficient genomic androgen receptor signaling is adequate to protect female mice from induction of polycystic ovary syndrome features by prenatal hyperandrogenization. Endocrinology. 2015;156:1441-52.

42. Franks S, Stark J, Hardy K. Follicle dynamics and anovulation in polycystic ovary syndrome. Hum Reprod Update. 2008;14:367-78.

43. Tyndall V, Broyde M, Sharpe R, Welsh M, Drake AJ, McNeilly AS. Effect of androgen treatment during foetal and/or neonatal life on ovarian function in prepubertal and adult rats. Reproduction. 2012;143:21.

44. Orisaka M, Tajima K, Tsang BK, Kotsuji F. Oocyte-granulosa-theca cell interactions during preantral follicular development. J Ovarian Res. 2009;2:1-7.

45. Yang M, Li J, An Y, Zhang S. Effects of androgen on immunohistochemical localization of androgen receptor and Connexin 43 in mouse ovary. Tissue Cell. 2015;47:526-32.

46. Pan J-X, Zhang J-Y, Ke Z-H, Wang F-F, Barry JA, Hardiman PJ et al. Androgens as double-edged swords: induction and suppression of follicular development. Hormones. 2015;14:190-200.

47. Kauffman AS, Thackray VG, Ryan GE, Tolson KP, Glidewell-Kenney CA, Semaan SJ et al. A novel letrozole model recapitulates both the reproductive and metabolic phenotypes of polycystic ovary syndrome in female mice. Biol Reprod. 2015;93:69, 1-12. 
48. Skarra DV, Hernández-Carretero A, Rivera AJ, Anvar AR, Thackray VG. Hyperandrogenemia induced by letrozole treatment of pubertal female mice results in hyperinsulinemia prior to weight gain and insulin resistance. Endocrinology. 2017;158:2988-3003.

49. Torres PJ, Skarra DV, Ho BS, Sau L, Anvar AR, Kelley ST et al. Letrozole treatment of adult female mice results in a similar reproductive phenotype but distinct changes in metabolism and the gut microbiome compared to pubertal mice. BMC Microbiol. 2019;19:1-15.

50. Tandulwadkar SR, Lodha PA, Mangeshikar NT. Obstetric complications in women with IVF conceived pregnancies and polycystic ovarian syndrome. J Hum Reprod Sci. 2014;7:13.

51. Zurvarra FM, Salvetti NR, Mason JI, Velazquez MM, Alfaro NS, Ortega HH. Disruption in the expression and immunolocalisation of steroid receptors and steroidogenic enzymes in letrozoleinduced polycystic ovaries in rat. Reprod Fertil Dev. 2009;21:827-39.

52. Baravalle C, Salvetti NR, Mira GA, Pezzone N, Ortega HH. Microscopic characterization of follicular structures in letrozole-induced polycystic ovarian syndrome in the rat. Med Res Arch. 2006;37:830-9.

53. Chaudhari N, Dawalbhakta M, Nampoothiri L. GnRH dysregulation in polycystic ovarian syndrome (PCOS) is a manifestation of an altered neurotransmitter profile. Reprod Biol Endocrinol. 2018;16:37.

54. Sir-Petermann T, Maliqueo M, Codner E, Echiburu B, Crisosto N, Pérez V et al. Early metabolic derangements in daughters of women with polycystic ovary syndrome. J Clin Endocrinol Metab. 2007;92:4637-42.

55. Feng Y, Johansson J, Shao R, Mannerås L, Fernandez-Rodriguez J, Billig H et al. Hypothalamic neuroendocrine functions in rats with dihydrotestosterone-induced polycystic ovary syndrome: effects of low-frequency electro-acupuncture. PLoS One. 2009;4.

56. Berg T, Silveira MA, Moenter SM. Prepubertal development of GABAergic transmission to gonadotropin-releasing hormone $(\mathrm{GnRH})$ neurons and postsynaptic response are altered by prenatal androgenization. J Neurosci. 2018;38:2283-93.

57. Moore AM, Prescott M, Marshall CJ, Yip SH, Campbell RE. Enhancement of a robust arcuate GABAergic input to gonadotropin-releasing hormone neurons in a model of polycystic ovarian syndrome. Proc Natl Acad Sci. 2015;112:596-601.

58. Silva MS, Desroziers E, Hessler S, Prescott M, Coyle C, Herbison AE et al. Activation of arcuate nucleus GABA neurons promotes luteinizing hormone secretion and reproductive dysfunction: Implications for polycystic ovary syndrome. EBioMedicine. 2019;44:582-96.

59. Cheng G, Coolen LM, Padmanabhan V, Goodman RL, Lehman MN. The kisspeptin/neurokinin $\mathrm{B} /$ dynorphin (KNDy) cell population of the arcuate nucleus: sex differences and effects of prenatal testosterone in sheep. Endocrinology. 2010;151:301-11.

60. Esparza LA, Schafer D, Ho BS, Thackray VG, Kauffman AS. Hyperactive LH pulses and elevated kisspeptin and NKB gene expression in the arcuate nucleus of a PCOS mouse model. Endocrinology. 2020;161:bqaa018.

61. Iwasa T, Matsuzaki T, Yano K, Mayila Y, Yanagihara R, Yamamoto Y et al. Prenatal undernutrition affects the phenotypes of PCOS model rats. J Endocrinol. 2018;239:137-51. 
62. Aliabadi E, Namavar MR, Mortezaee K, Toolee H, Keshtgar S, Mirkhani H et al. Kisspeptin expression features in the arcuate and anteroventral periventricular nuclei of hypothalamus of letrozole-induced polycystic ovarian syndrome in rats. Arch Gynecol Obstet. 2017;296:957-63.

63. Osuka S, Iwase A, Nakahara T, Kondo M, Saito A, Nakamura T et al. Kisspeptin in the hypothalamus of 2 rat models of polycystic ovary syndrome. Endocrinology. 2017;158:367-77.

64. Iwasa T, Matsuzaki T, Tungalagsuvd A, Munkhzaya M, Kuwahara A, Yasui T et al. The advancement of the onset of vaginal opening in female rats subjected to chronic testosterone treatment occurs independently of hypothalamic Kiss1 and RFRP expression. Neuro Endocrinol Lett. 2015;36:767-70.

65. Poling MC, Shieh MP, Munaganuru N, Luo E, Kauffman AS. Examination of the influence of leptin and acute metabolic challenge on RFRP-3 neurons of mice in development and adulthood. Neuroendocrinology. 2014;100:317-33.

\section{Tables}

Table 1. Real-time PCR primers for target and reference genes and annealing temperatures.

\begin{tabular}{|c|c|c|c|c|}
\hline Gene & \multicolumn{2}{|c|}{ Sequence } & $\begin{array}{l}\text { Product size } \\
\text { (bp) }\end{array}$ & $\begin{array}{l}\text { Annealing temperature } \\
\left({ }^{\circ} \mathrm{C}\right)\end{array}$ \\
\hline \multirow[t]{2}{*}{$\mathrm{GnRH}$} & Forward & $\begin{array}{l}\text { 5'- } \\
\text { AATACTGAACACTTGGTTGA-3' }\end{array}$ & 20 & 57 \\
\hline & Reverse & 5'-AGATCCCTAAGAGGTGAA-3' & 18 & \\
\hline \multirow{2}{*}{$\begin{array}{l}\text { RFRP- } \\
3\end{array}$} & Forward & 5'-AAGACACTGGCTGGTTTG-3' & 18 & 56 \\
\hline & Reverse & 5'-TTGAAGGACTGGCTGGAG-3' & 18 & \\
\hline \multirow[t]{2}{*}{$\beta$-actin } & Forward & 5'-CACAGCTGAGAGGGAAAT-3' & 18 & 56 \\
\hline & Reverse & 5'-TCAGCAATGCCTGGGTAC-3' & 18 & \\
\hline
\end{tabular}

\section{Figures}




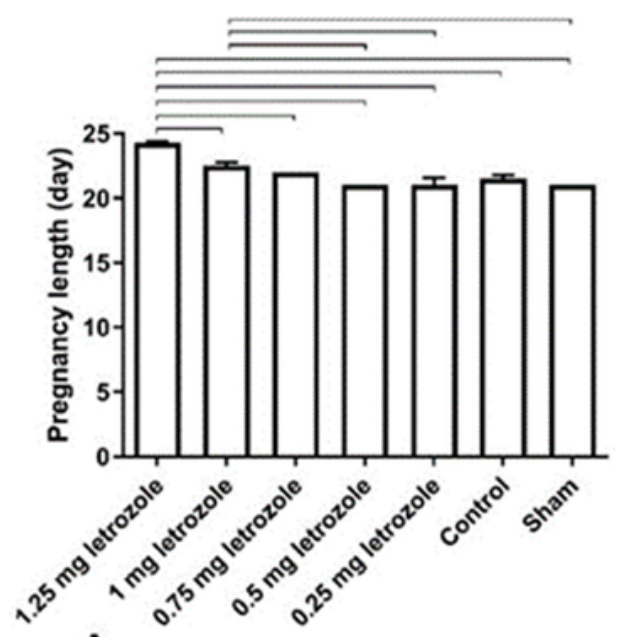

A
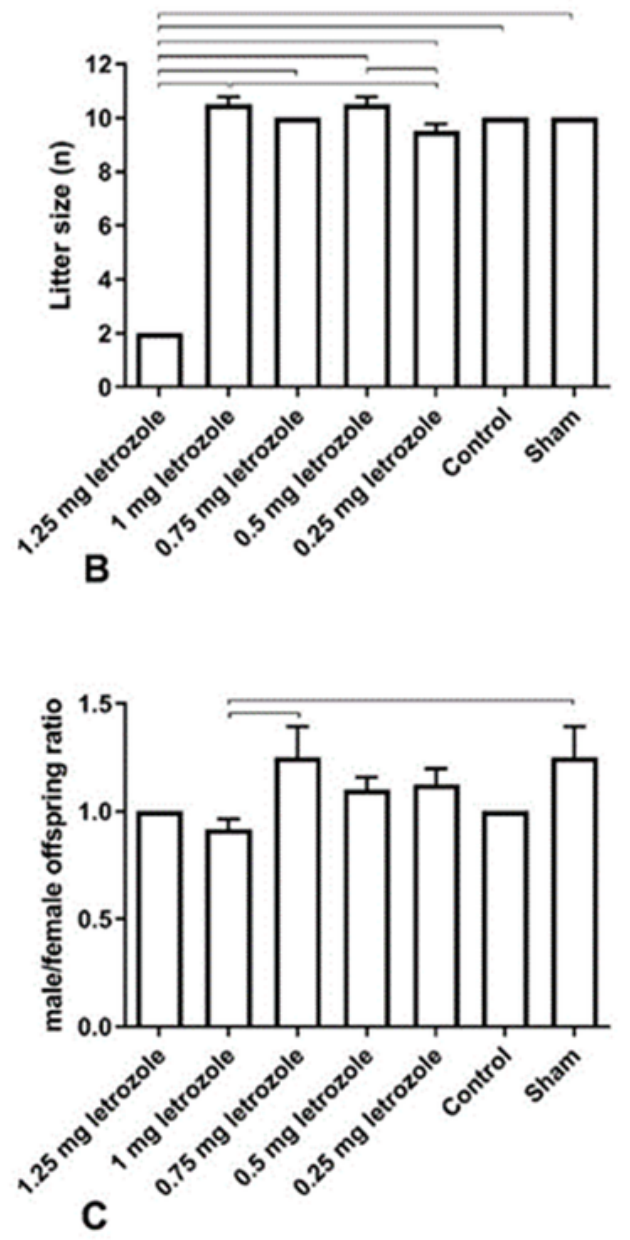

Figure 1

Prenatal PCOS induced effects on gestation length (A), litter size (B), and male/female offspring ratio (C) in adult rats (mean $\pm S E M$ ). The lines show significant differences between groups at $P<0.05$. 

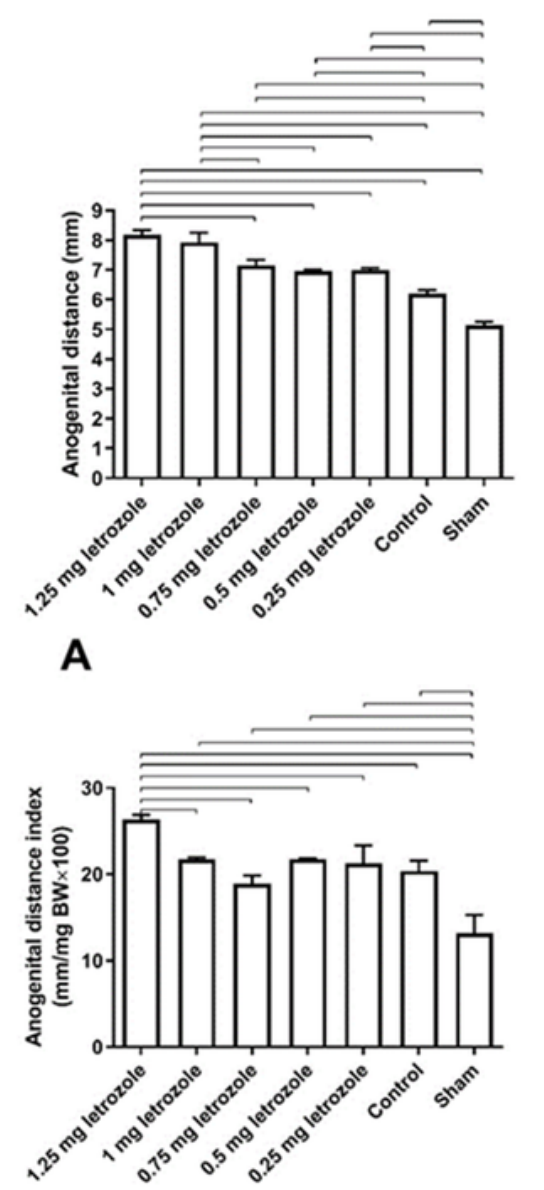

B

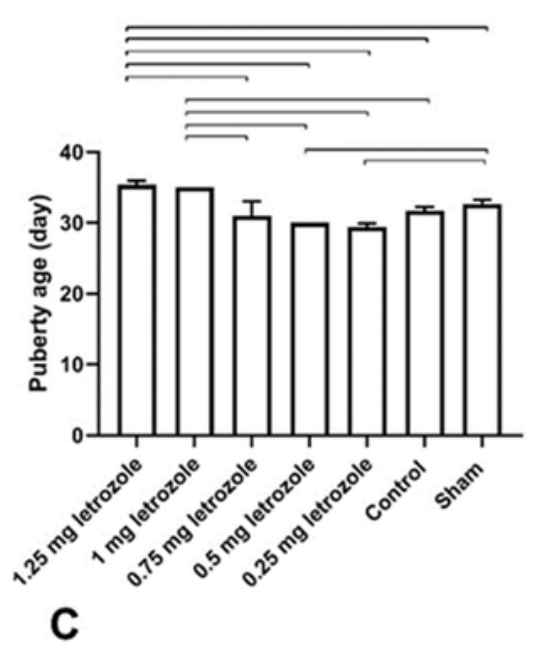

Figure 2

Prenatal PCOS induced effects on anogenital distance (AGD, A), AGD index (AGDI, B) and puberty age (C) in adult rats (mean $\pm S E M$ ). The lines show statistical significant differences between groups at $P<0.05$. 


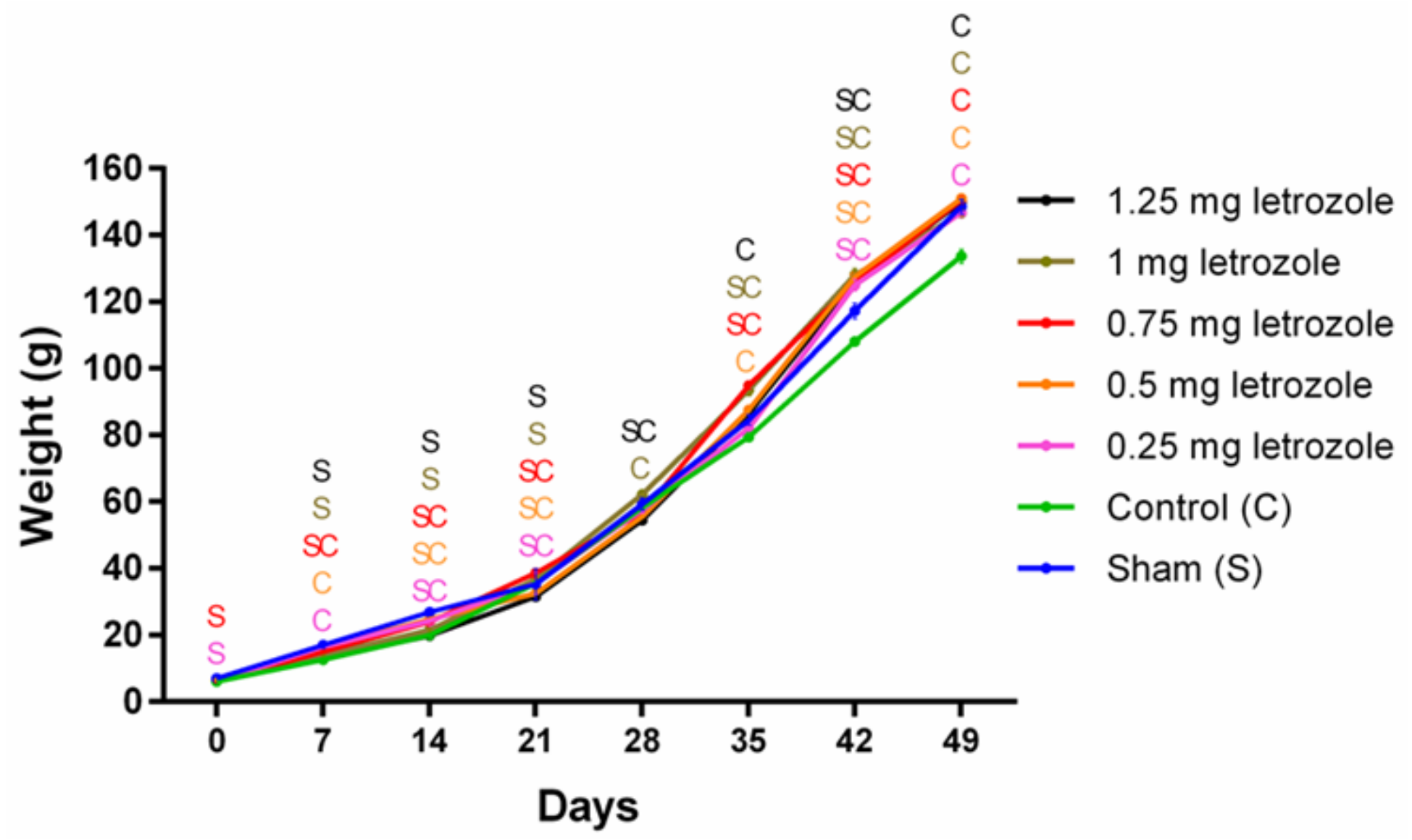

Figure 3

Prenatal PCOS induced effects on body weight gain in adult rats (mean + SEM). S,C; The superscript letters show statistical significant differences between letrozole-treated groups with control and sham groups in each day $(P<0.05)$. 

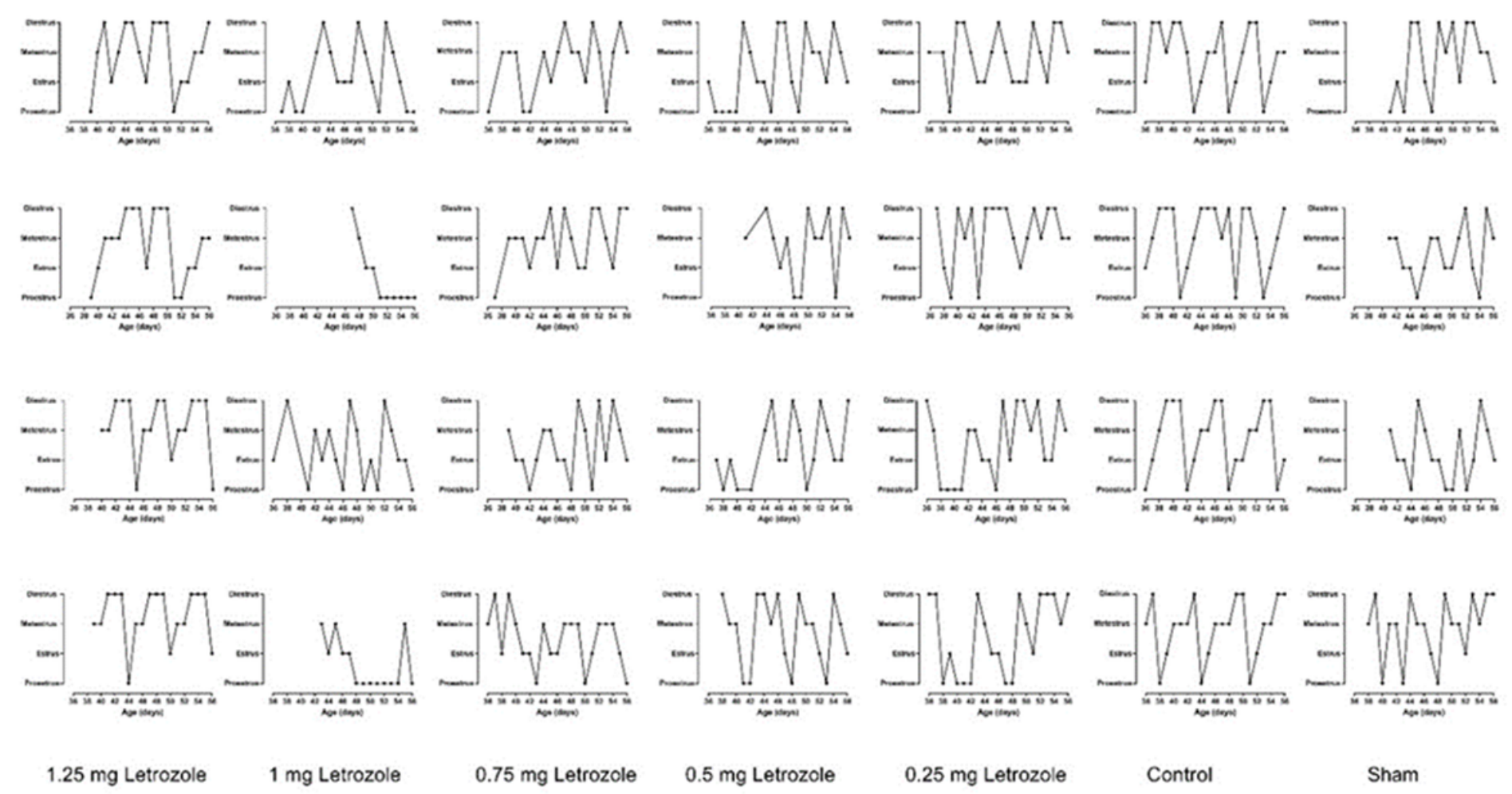

\section{Figure 4}

Prenatal PCOS induced effects on estrous cycle patterns during three weeks daily observations in adult rats. 


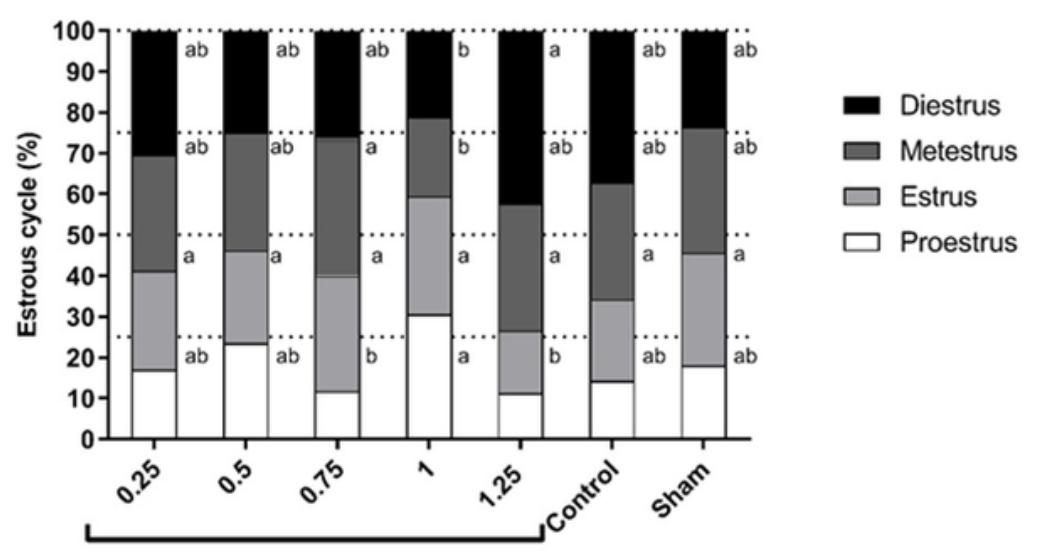

A Letrozole $(\mathrm{mg} / \mathrm{kg})$
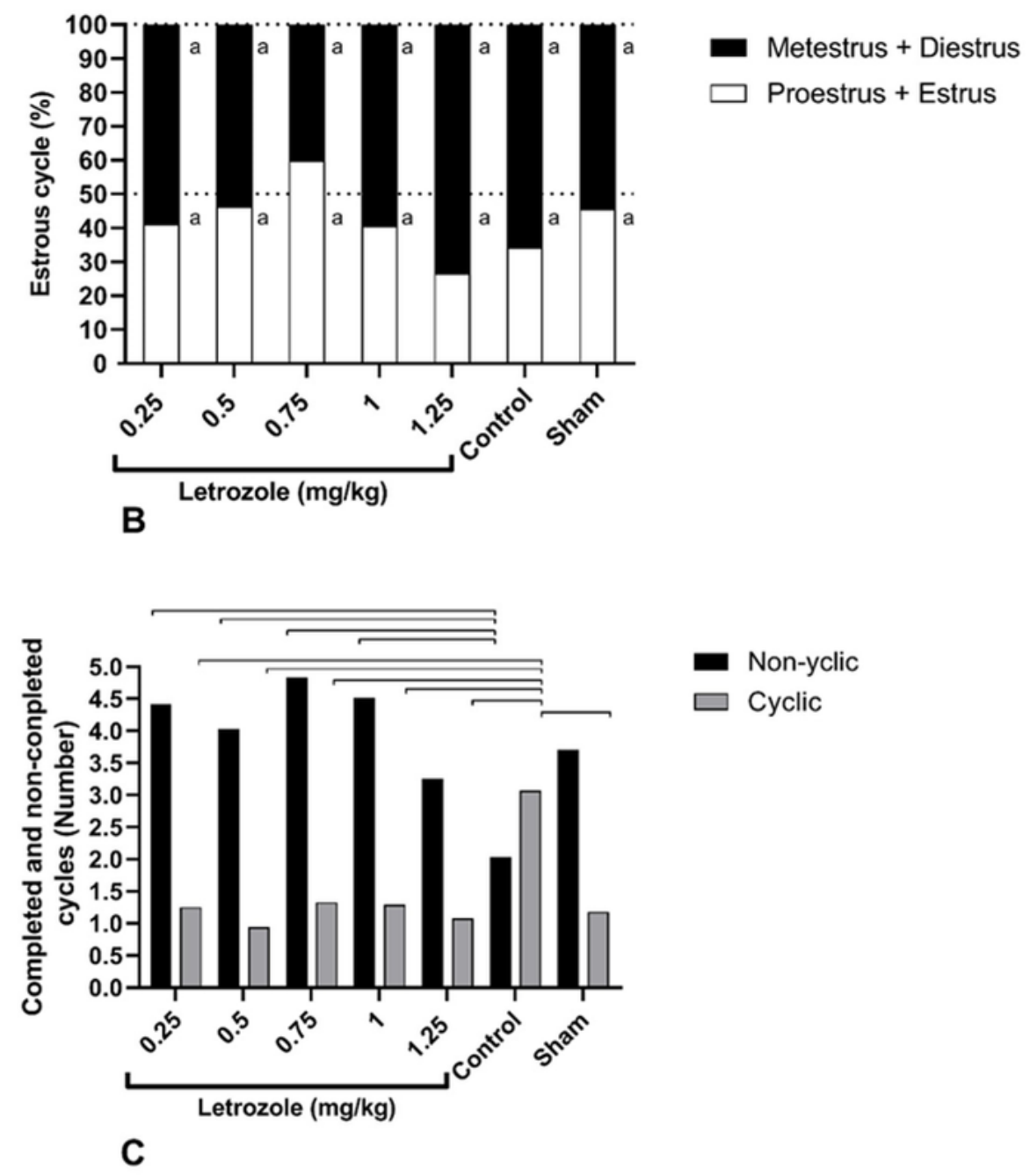

Figure 5

Prenatal PCOS induced effects on estrous cycle \% (A), proestrous + estrous and metestrous + diestrous phases \% (B) and number of completed and incomplete cycles (C) in letrozole-treated and control groups $($ mean + SEM). The lines show statistical significant difference between groups at $P<0.05$. 

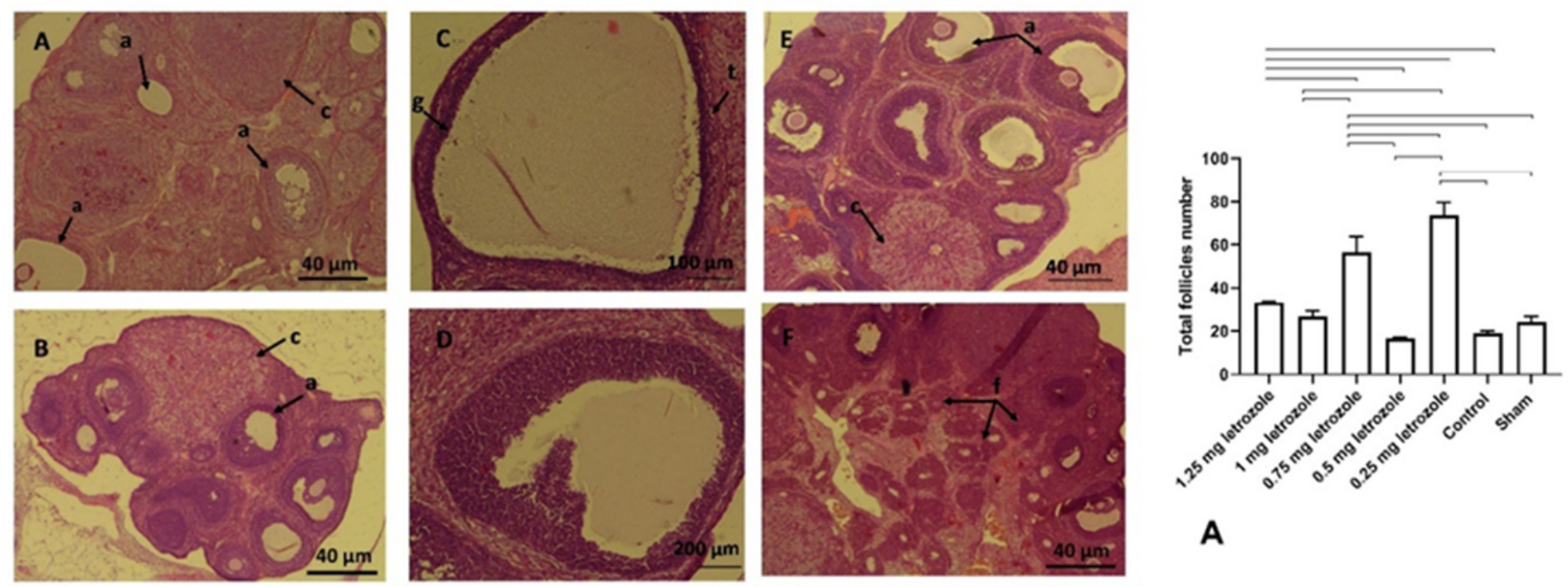

A

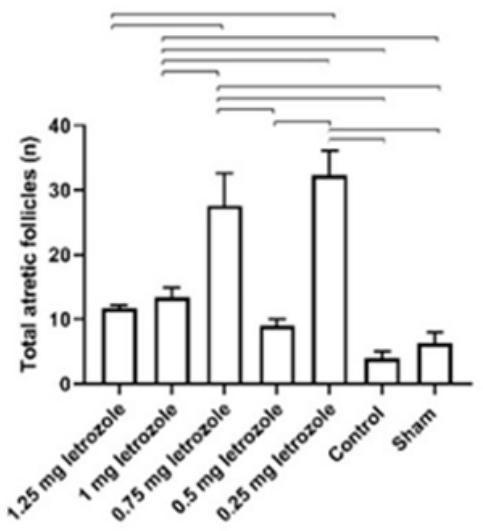

B
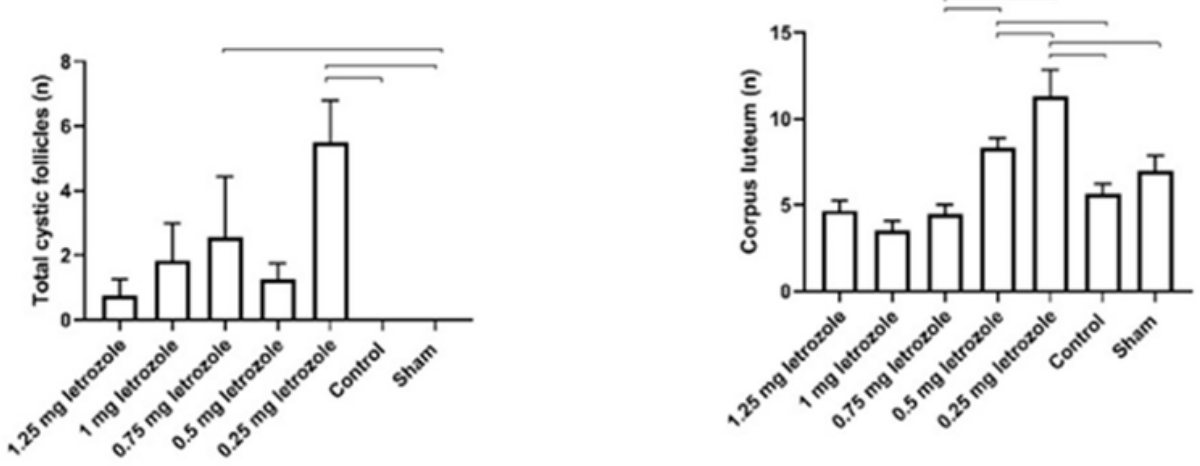

D

\section{Figure 6}

Prenatal PCOS induced effects on number of total follicles (A), number of atretic follicles (B), number of cystic follicles (C) and number of corpus luteum (D) (mean + SEM), and hematoxylin-eosin staining of rat ovaries in letrozole-treated and control groups. Ovarian tissue in the control group (A) that has corpus luteum (c) and antral follicles (a) ovarian tissue in the $0.75 \mathrm{mg}$ group (B), which has more antral follicles and corpus luteum (c), ovarian tissue in the $0.25 \mathrm{mg}$ group (C), which has a large cystic follicle with a thin granulosa layer $(\mathrm{g})$ and theca layer $(\mathrm{t})$, large cyst in the $0.75 \mathrm{mg}$ group (D), ovarian tissue in the $0.25 \mathrm{mg}$ group (E) has a large number of antral follicles (a) as well as corpus luteum (c), ovarian tissue in $1 \mathrm{mg}$ group (F), which has a large number of growing follicles (f) and antral follicles. The lines show statistical significant difference between groups at $\mathrm{P}<0.05$. 


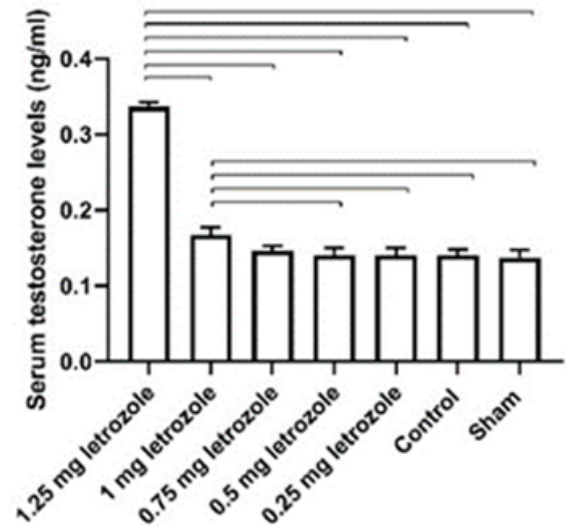

A

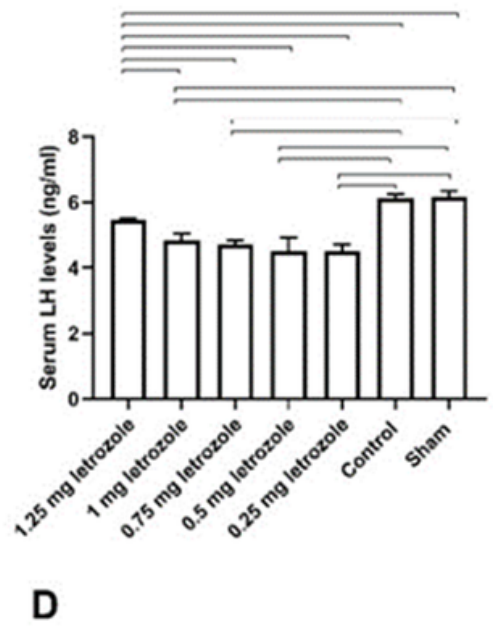

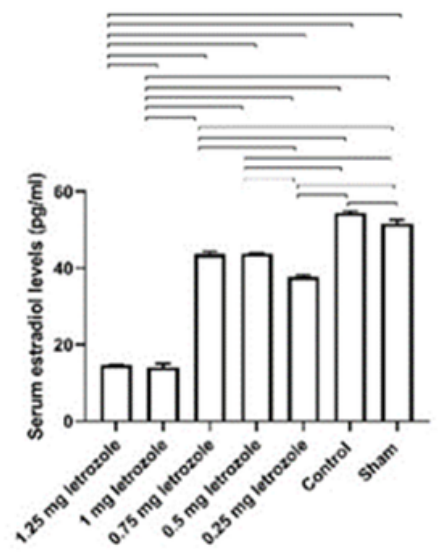

B

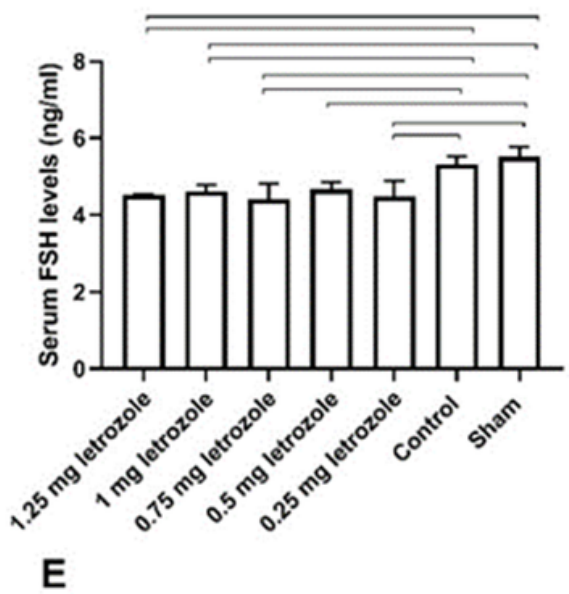

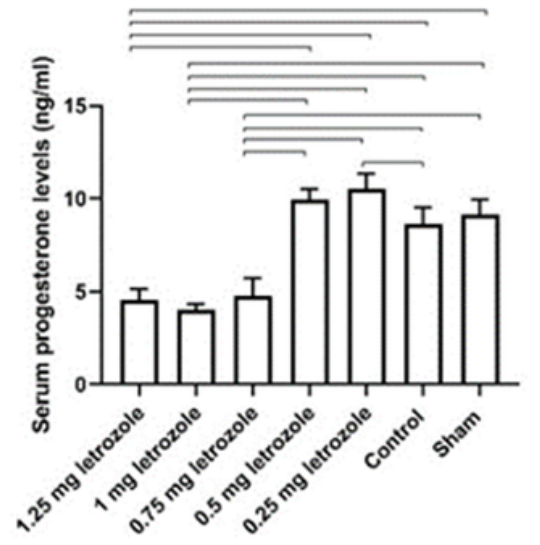

C

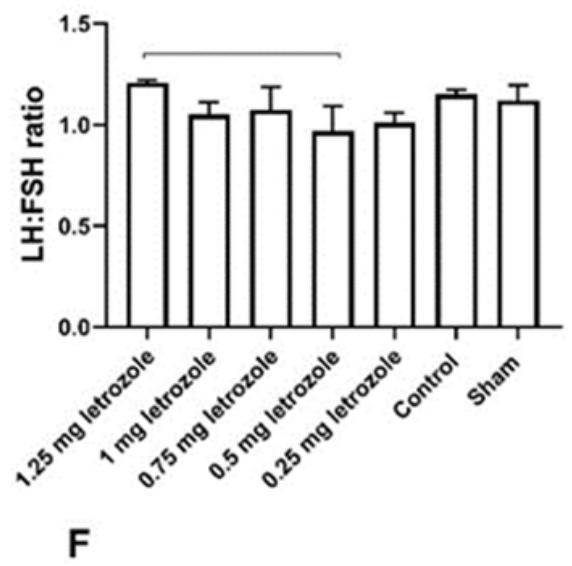

Figure 7

Prenatal PCOS induced effects on serum concentration of testosterone (A), estradiol (B), progesterone (C) $\mathrm{LH}(\mathrm{D}), \mathrm{FSH}(\mathrm{E})$ and LH: FSH ratio (F) (mean + SEM) in adult rats. The lines show statistical significant difference between groups at $\mathrm{P}<0.05$. 


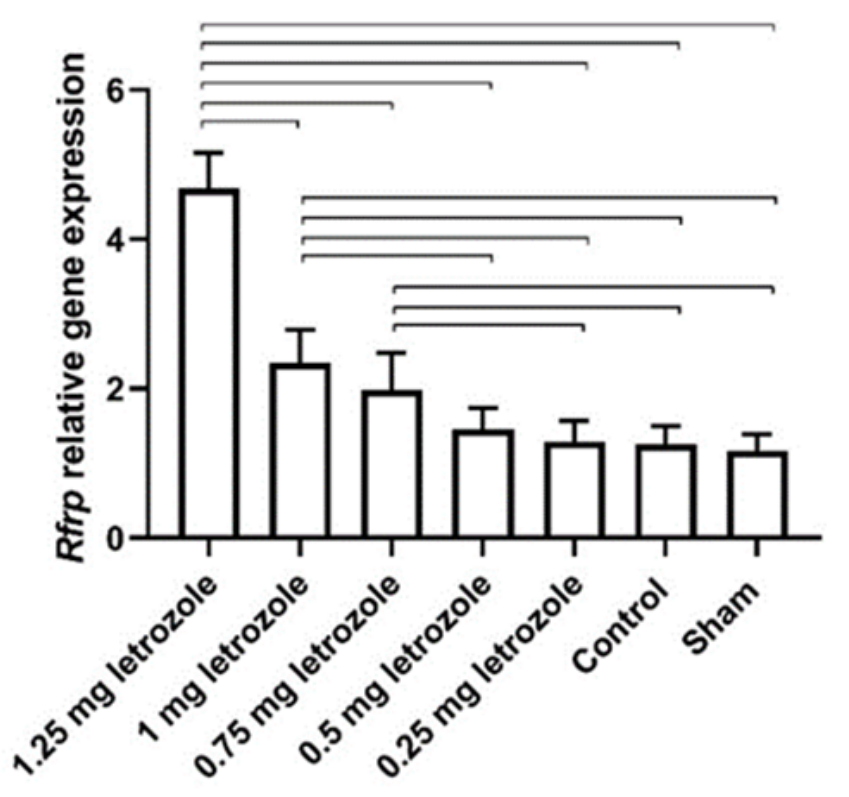

A

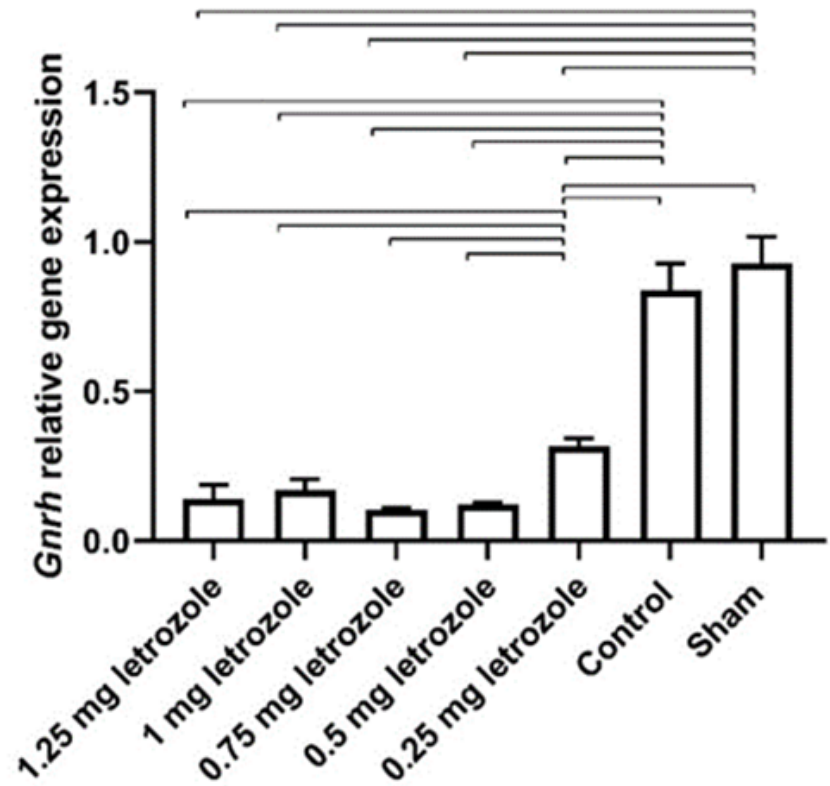

B

Figure 8

Prenatal PCOS induced effects on relative gene expression of Rfrp (A) and Gnrh (B) (mean + SEM) in adult rats. The lines show statistical significant difference between groups at $P<0.05$. 